\title{
Família, adolescência e estilos parentais ${ }^{1}$
}

\section{Family, teenagers and parenting styles}

\author{
Claudia Maria RINHEL-SILVA² \\ Elizabeth Piemonte CONSTANTINO ${ }^{3}$ \\ Carina Alexandra RONDINI ${ }^{3}$
}

\begin{abstract}
Resumo
O objetivo principal deste trabalho foi identificar os estilos parentais característicos de famílias provenientes de contextos de alta vulnerabilidade social. A amostra foi composta por 62 adolescentes, com idade entre 12 e 17 anos, de ambos os sexos, e suas respectivas famílias. Para a coleta de dados, utilizou-se uma escala de exigência e responsividade, aplicada de forma coletiva nos adolescentes, além da análise de documentos constantes nos prontuários das famílias. Os resultados principais indicaram que as famílias eram geralmente numerosas, com estruturas diversas, e que os adolescentes percebiam seus pais mais como autoritativos do que como negligentes.
\end{abstract}

Unitermos: Adolescentes. Contexto familiar. Estilos parentais.

\begin{abstract}
The goal of this research was to identify parenting styles among families from contexts of high social vulnerability. We therefore interviewed 62 teenagers of both sexes between the ages of 12 and 17 and their respective families. Research tools employed a scale of demandingness and responsiveness applied collectively to the teenagers and an analysis was undertaken of documents from the families' files. The main findings showed that such families were normally large and varied in structure and that the teenagers perceived their parents to be more authoritative than negligent.
\end{abstract}

Uniterms: Adolescents. Familiar context. Parental styles.

Em programas sociais para adolescentes em situação de alta vulnerabilidade social ${ }^{4}$, desenvolvidos pela Secretaria Municipal de Assistência Social do município de Assis/SP, no qual se atua como psicólogos em orientação de pais, têm surgido várias questões envolvendo as relações familiares, como resultado do enfraquecimento da autoridade dos pais. Parece estar havendo uma transformação de valores, na qual os pais ocupam o lugar dos filhos e vice-versa, o que pode causar um descontrole das ações familiares. Nos dias

\section{$\boldsymbol{\nabla} \boldsymbol{\nabla} \boldsymbol{\nabla}$}

1 Artigo elaborado a partir da dissertação de C.M. RINHEL-SILVA, intitulada "Família, adolescência e estilos parentais". Universidade Estadual Paulista Júlio de Mesquita Filho, 2009.

2 Universidade Estadual Paulista Júlio de Mesquita Filho, Programa de Pós-Graduação em Psicologia. Av. Dom Antonio, 2100, 19806-900, Assis, SP, Brasil. Correspondência para/Correspondence to: E.P. CONSTANTINO.E-mails: <bethpie@assis.unesp.br>; <claudiarinhel@uol.com.br>.

3 Universidade Estadual Paulista Júlio de Mesquita Filho, Departamento de Psicologia Experimental e do Trabalho. Assis, SP, Brasil.

4 Vulnerabilidade Social divide-se em alta e baixa, conforme o Índice Paulista de Vulnerabilidade (IPVS): esse índice "é resultante da combinação da dimensão socioeconômica, ou seja, a renda apropriada pelas famílias e o poder de geração da mesma por seus membros, associada a uma dimensão demográfica, relacionada ao local de moradia e à fase do ciclo de vida familiar, que potencializa riscos ..." (Macedo, Kubilowski \& Berthoud, 2006, p.43). 
atuais, os pais demonstram estar com dificuldades para lidar com a educação dos filhos, no que se refere aos limites.

Para entendimento das relações entre pais e filhos, foi realizado este estudo, no ano de 2008, com o objetivo de identificar a maneira como os adolescentes percebem os estilos parentais em famílias sujeitas a vulnerabilidade social.

Observa-se que os pais não conseguem equilibrar amor e limites e, apreensivos com a preocupação de traumatizar os filhos, deixam de estabelecer expectativas firmes para que eles amadureçam e se tornem independentes. A dimensão do afeto parece ter tomado espaço, principalmente nas relações de pais e filhos, o que provavelmente aconteceu, segundo Reichert e Wagner (2007), por uma leitura equivocada, feita nos anos 1970, das inovações educativas que preconizavam a importância do amor em detrimento de uma educação mais rígida, ou seja, monitorada e controlada. Assim, as famílias começaram a refutar as ações de controlar e monitorar, ao buscar uma melhor qualidade da interação entre pais e filhos.

A conduta dos pais em relação aos filhos está intimamente ligada à colocação de regras, normas e limites, pois, desde os primeiros anos de vida, o bebê começa a construir seu referencial de atitudes por meio do"olhar" e do comportamento do adulto. Recebe orientações a respeito do que é importante para preservar e defender a vida, como habilidades sociais e estímulos para crescer. Essa conduta é que possivelmente permitirá a constituição do referencial de limites e a posterior formação de sua personalidade e conduta em sociedade.

Para pensar a problemática relativa às interações familiares, isto é, como os adultos estão se comportando na questão de limites e educação dos filhos, têm sido realizados estudos na abordagem de estilos parentais. Ao longo do tempo, tal abordagem tornou-se uma das mais utilizadas formas de investigação acerca das interações socializadoras na família e sua influência sobre os filhos (Teixeira, Bardagi \& Gomes, 2004).

O estilo parental refere-se a um padrão de comportamento dos pais, expresso num clima emocional criado pelo conjunto de suas atitudes, como as práticas disciplinares e outros aspectos de sua interação com os filhos (Darling \& Steinberg, 1993).

Alguns estudos precursores, que se destacam no entendimento das relações entre pais e filhos, são os de Baumrind (1966, 1967, 1971). A autora discute as modalidades de controle parental, tomando os pais como tipos especiais de liderança. Assim, investigou o modo como os diferentes padrões de controle parental poderiam afetar o desenvolvimento dos filhos, usando como amostra crianças pré-escolares e seus pais. Os resultados do estudo indicaram três tipos (chamados posteriormente de estilos) de controles parentais - autoritário, autoritativo ${ }^{5}$ e permissivo -, sendo o estilo considerado como o contexto dentro do qual os pais agem para socializar os filhos, de acordo com suas crenças e valores (Darling \& Steinberg, 1993).

Maccoby e Martin (1983) analisaram os estilos parentais em termos do cruzamento das dimensões exigência e responsividade. Na pesquisa, mantiveram os estilos autoritário e autoritativo, propostos por Baumrind (1967, 1971), ampliando o padrão permissivo em dois novos estilos: indulgente e negligente. Assim, os três estilos fixados inicialmente pela autora foram transformados em quatro, passando a ser definidos por meio das dimensões de exigência e responsividade ${ }^{6}$.

A dimensão exigência (demandingness) diz respeito ao controle do comportamento e ao estabelecimento de metas e padrões de conduta que inclui todas as atitudes dos pais que buscam de alguma forma controlar o comportamento dos filhos, impondo-Ihes limites e estabelecendo regras. ... a dimensão responsividade (responsiveness), cujo termo origina-se na perspectiva etológica e diz respeito à sincronicidade entre comportamento de filhos e de cuidadores, está relacionada à capacidade dos pais em serem contingentes ao atender às necessidades e às particularidades dos filhos (Teixeira et al., 2004, p.2).

Ainda mencionando características da dimensão responsividade, Maccoby e Martin (1983) acrescentam que os pais se mostram amorosos, responsivos e envolvidos com os filhos. Articulando com os estilos propostos por Baumrind (1966), os autores, conforme se frisou,

\footnotetext{
5 O termo autoritativo origina-se do termo original authoritative, traduzido por pesquisadores brasileiros (Costa, Teixeira \& Gomes, 2000).

222 - Termos correspondentes a demandingness e responsiveness, respectivamente, no original em inglês.
} 
definem quatro estilos de criação de filhos pelos pais: autoritativo (níveis altos de exigência e responsividade); autoritário (nível alto de exigência e baixo de responsividade); indulgente (nível alto de responsividade e baixo de exigência) e negligente (níveis baixos de exigência e responsividade).

Embora vários estudiosos internacionais sobre o assunto tenham desenvolvido instrumentos para analisar os estilos parentais, pesquisadores brasileiros (Costa et al., 2000; Gomide, 2006; Teixeira et al., 2004) também aprimoraram instrumentos, com o intuito de estudar os padrões de interação familiar e de melhorar as interações familiares quanto à educação dos filhos.

Os estudos citados mostraram-se importantes na construção e investigação da influência do comportamento dos pais sobre os filhos adolescentes. A fim de que os pais possam exercer papel de educadores ou mesmo contribuir para a saúde mental de seus filhos, é importante, de acordo com as pesquisas, equilibrar os estilos parentais de exigência e responsividade; para tanto, pensa-se que eles devem ser investidos de autoridade, o que provavelmente vem do conhecimento e da experiência de vida.

Os resultados de algumas investigações demonstram a importância dos estilos parentais no comportamento dos filhos. Reichert e Wagner (2007) apontam que o desenvolvimento da autonomia parece estar relacionado com os estilos educativos adotados pelos pais. Em seu trabalho, realizado com 168 jovens, é possível notar que, na percepção do adolescente, a maioria dos pais são considerados, em relação aos estilos parentais, como negligentes e autorizantes (autoritativos). Destacou-se também que os pais têm o mesmo nível de exigência tanto para os meninos quanto para as meninas, porém, na dimensão responsividade, os dados mostraram que os pais se apresentam mais responsivos com os filhos do que com as filhas. Foi observado igualmente, na amostra, que um dos fatores que parece interferir na relação entre pais e filhos, no sentido de enfraquecê-la, é o fato de a maioria dos pais trabalhar fora $(63,7 \%)$, estando menos disponíveis para os filhos. Não se evidenciou correlação entre estilos parentais e autonomia, na pesquisa; todavia, pode-se considerar que a mãe é a figura mais presente no processo de educação dos filhos. Na conclusão do estudo, o equilíbrio de ambos os pais quanto aos estilos parentais é consi- derado um fator de proteção, visto pelo bom desempenho acadêmico dos adolescentes da amostra.

No trabalho empreendido por Hutz e Bardagi (2006), com o objetivo de avaliar as possíveis correlações entre os estilos parentais percebidos pelos adolescentes e seus níveis de indecisão profissional, ansiedade e depressão, com 467 adolescentes de 15 a 20 anos, os autores observaram que filhos de pais com os estilos parentais autoritários e negligentes apresentaram maior nível de depressão e ansiedade que os outros. No que tange à indecisão profissional, não foram encontradas correlações, entretanto, pôde-se verificar a importância das interações familiares para o entendimento de como a indecisão profissional está sendo vivenciada.

Outras pesquisas mostram a importância dos estilos parentais no desenvolvimento de crianças e de adolescentes. Weber, Brandenburg e Viezzer (2003a) evidenciaram que $54,0 \%$ das crianças otimistas são filhos de pais participativos ou autoritativos. Também Weber, Stasiack e Brandenburg (2003b) constataram que 63.0\% dos adolescentes com autoestima elevada eram filhos de pais com o estilo parental participativo ou autoritativo.

Steinberg (2001) salienta que adolescentes criados em lares de estilo parental autoritativo apresentam menor depressão e ansiedade, maiores notas na escola, maior autoconfiança e autoestima e ainda são menos propensos a comportamentos antissociais, delinquência e drogas. Pode-se observar, mediante os resultados das pesquisas, que o estilo parental autoritativo mostrou ser o mais adequado para uma educação saudável dos filhos. Nesse sentido, os pais precisam ser firmes em relação a certa autoridade (ou seja, no nível de exigência) e, ao mesmo tempo, responsivos no respeito e compreensão dos direitos dos filhos.

A pesquisa de Weber, Selig, Bernardi \& Salvador (2006), na qual os autores se propuseram a investigar a transmissão intergeracional dos estilos parentais em 21 mulheres, respeitando a linearidade trigeracional, revelou que a transmissão intergeracional de estilos parentais aparece com um índice de 91,7\%, ao passo que apenas para 8,3\% dos sujeitos analisados a transmissão dos estilos parentais não foi efetivada.

A partir dos estudos mencionados e da prática profissional na área da Assistência Social, questiona-se como os adolescentes percebem os estilos parentais 
característicos de famílias provenientes de contextos de alta vulnerabilidade social. Assim, a identificação desses estilos pelos adolescentes constituiu o objetivo principal da presente pesquisa.

\section{Método}

\section{Participantes}

Trata-se de uma amostra por conveniência, composta por 62 adolescentes (40 meninos e 22 meninas), de 12 a 17 anos, que frequentavam o programa social Adolescer, da Secretaria Municipal de Assistência Social da cidade de Assis (SP), e suas respectivas famílias.

Os adolescentes pertencem a diversos arranjos familiares e estão inseridos num contexto de alta vulnerabilidade social: residem em bairros periféricos do município, em áreas com focos de drogadição avaliados como territórios críticos. Provêm de espaços caracterizados por distintos fatores geradores de vulnerabilidade: moradias precárias, baixa renda familiar, drogadição, pouca ou nenhuma qualificação profissional; sobrevivem de subempregos (trabalhadores rurais, catadores de materiais reciclados, entre outros) e necessitam de intervenções assistenciais para seu sustento.

Neste estudo, foi utilizada uma escala que avalia os estilos parentais, ou seja, as dimensões de exigência e responsividade, por meio de frases de autorrelato (Teixeira et al., 2004). Cada escala é composta por 12 itens, do tipo Likert de 5 pontos.

As famílias dos adolescentes foram caracterizadas quanto a sua configuração familiar e número de trabalhadores, a partir dos prontuários cadastrados na Secretaria Municipal de Assistência Social de Assis.

Os dados foram colhidos na própria Secretaria Municipal de Assistência Social, especificamente nas instalações do Programa Adolescer, que atende em média a 100 adolescentes por dia. Para apresentação da proposta de pesquisa, foi feita uma reunião com todos os adolescentes, quando foram esclarecidos os objetivos e formalizados os convites para a participação no estudo. Aqueles que aceitaram o convite receberam o Termo de Consentimento Livre e Esclarecido, que foi por eles lido e assinado, e levado para que seus pais 224 autorizassem e ratificassem a participação na pesquisa.

\section{Instrumentos}

Realizou-se, num primeiro momento, a caracterização das famílias dos adolescentes, por meio de análise documental. Foi solicitado aos sujeitos participantes que respondessem ao instrumento - escala de responsividade e exigência - no qual deveriam avaliar pai e mãe (ou figuras de referência) separadamente. Entendeu-se como relevante que fossem mencionadas, no início da escala, as figuras de referência, pois muitos dos adolescentes residiam com outras pessoas, que exerciam o papel de pai e/ou mãe.

Os resultados da escala de exigência e responsividade foram analisados segundo critérios especificados em Teixeira et al. (2004), segundo os quais os escores representam a soma dos itens que compõem cada uma das escalas, separadamente para pai e mãe. No caso dos escores combinados, foram somados os itens concernentes a pais e mães para cada uma delas.

\section{Análise estatística}

Para estudar a existência de diferenças entre os sexos para as variáveis exigência e responsividade de pais, mães e combinadas, foi usado o teste t para amostras independentes, com nível de significância de 5\%. A fim de verificar a existência de diferenças entre as variáveis exigência e responsividade, para meninos e meninas, foi utilizado o teste $t$ para dados pareados. Também foi empregado o teste Qui-Quadrado, com a finalidade de investigar possíveis diferenças entre sexos nas classificações dos estilos parentais (combinação de exigência e responsividade), a partir dos escores combinados de pai e mãe.

Os índices de consistência interna (alpha de Cronbach), obtidos na análise da escala de exigência, foram: 0,85, para pais e mães combinados; 0,87, para os pais; 0,91, para as mães. Os índices de consistência interna, obtidos na análise da escala de responsividade, foram: para pais e mães combinados, 0,85; para os pais, 0,86 e, para as mães, 0,90. Os índices encontrados podem ser considerados adequados para as análises efetivadas.

A realização do estudo foi aprovada pelo Comitê de Ética do Hospital Regional de Assis, Parecer no 157/2008, atendendo aos requisitos de pesquisa com 
seres humanos, conforme Resolução n 196, de 10 de outubro de 1996, da Comissão Nacional de Ética em Pesquisa.

\section{Resultados e Discussão}

Observa-se (Tabela 1), que a configuração familiar, tanto dos meninos como das meninas, evidencia diver-sidades em relação ao vínculo parental, em conso-nância com os dados mencionados por outras pesqui-sas, como as do Instituto Brasileiro de Geografia e Esta-tística (IBGE) (Brasil, 2006) e de Goldani (1993).

Verificou-se também que, do total de mães ( $n=59)$, a maioria, 44 (74,6\%), trabalha; quanto aos pais $(n=28)$ e padrastos $(n=21)$, todos trabalham (Tabela 1). 0 fato de os pais trabalharem fora, de acordo com Pereira (1995) e Reichert e Wagner (2007), pode ser um dos fatores que interfere na relação entre pais e filhos, no sentido de enfraquecê-la, visto que ficam pouco disponíveis tanto para cuidar da casa como dos filhos. A situação confirma as queixas dos pais, quando enfatizam que têm que trabalhar a fim de garantir o sustento familiar e que não há tempo para educar e impor limites aos filhos, ficando a tarefa, muitas vezes, para a escola ou até mesmo para a mídia.

Vê-se que as famílias dos meninos são mais numerosas que as das meninas, bem como contam com número maior de familiares que trabalham. No que tange a famílias numerosas, Cecconello (2003) e Predebon e Wagner (2005) as entendem como um dos fatores de prevalência de problemas de comportamento em adolescentes, destacando, ainda, como fator de maior risco, o baixo nível socioeconômico, que engloba a pobreza, a baixa remuneração parental, a baixa escolaridade dos pais, a ausência de um dos pais, aliados ao contexto onde os adolescentes se inserem. A investigação parece estar em consonância com os dados aqui apresentados, em que as famílias, além de serem numerosas, residem em bairros periféricos do município, em situação de alta vulnerabilidade social, conforme mencionado pelo Índice Paulista de Vulnerabilidade Social - IPVS (São Paulo, 2000).

A maioria das meninas (19-86,4\%) e dos meninos (38 - 95,0\%) referiu-se à mãe como desempenhando o "papel maternal". Quanto ao "papel do pai", 10 (55.6\%) meninas indicaram o próprio pai, enquanto 6 (33,3\%) apontaram o padrasto. Dentre os meninos, 22 (71,0\%) referiram-se ao pai, e 6 (19,4\%) mencionaram o padrasto. Outro dado importante é que, do total de meninos, mais da metade (25 - 62,5\%) possui pai ou padrasto que exerce o papel de pai, enquanto entre as meninas esse percentual é ligeiramente menor (59,1\%) 13 meninas (Tabela 1).

Diante dos novos arranjos familiares, a figura de referência para os filhos é quem desempenha o papel de imposição do limite, da autoridade e da realidade, além de acumular a função do cuidado e da afetividade, conforme ressaltam Wagner, Falke, Silveira e Mosmann (2002) e Zamberlan (2008).

Pode-se notar, quando se compara a dimensão exigência materna, que os meninos apresentam em média escores mais altos $(39,3)$ que as meninas $(36,7)$ (Tabela 2). Ainda em relação à exigência, agora avaliando

Tabela 1. Configuração familiar e pessoas economicamente ativas, segundo o sexo dos adolescentes ( $n=62)$. Assis (SP), 2008.

\begin{tabular}{|c|c|c|c|c|c|c|c|c|}
\hline \multirow{3}{*}{ Familiares } & \multicolumn{4}{|c|}{ Meninas $(n=22)$} & \multicolumn{4}{|c|}{ Meninos $(n=40)$} \\
\hline & \multicolumn{2}{|c|}{ Configuração familiar } & \multicolumn{2}{|c|}{ Trabalhadores } & \multicolumn{2}{|c|}{ Configuração familiar } & \multicolumn{2}{|c|}{ Trabalhadores } \\
\hline & $\mathrm{n}$ & $\%$ & $n$ & $\%$ & $n$ & $\%$ & $n$ & $\%$ \\
\hline Mãe & 20 & 90,9 & 14 & 70,0 & 39 & 97,5 & 30 & 76,9 \\
\hline Pai & 10 & 45,5 & 10 & 100,0 & 18 & 45,0 & 18 & 100,0 \\
\hline Padrasto & 3 & 13,6 & 3 & 100,0 & 7 & 17,5 & 7 & 100,0 \\
\hline Avó/Avô & 2 & 9,1 & 1 & 50,0 & 7 & 17,5 & 2 & 28,6 \\
\hline Tia/Tio & 2 & 9,1 & 2 & 100,0 & 5 & 12,5 & 1 & 20,0 \\
\hline Irmã(ão) & 15 & 68,2 & 1 & 6,7 & 31 & 77,5 & 6 & 19,4 \\
\hline Prima(o) & 0 & 0,0 & 0 & 0,0 & 1 & 2,5 & 0 & 0,0 \\
\hline Sobrinha(o) & 0 & 0,0 & 0 & 0,0 & 2 & 5,0 & 0 & 0,0 \\
\hline
\end{tabular}


o pai, pode-se ver que os pais são tratados como mais exigentes com os meninos $(32,1)$ do que com as meninas $(24,2)$.

Quando se analisa a dimensão responsividade para mãe e pai, separadamente, percebe-se que as mães das meninas apresentam escore médio de 36,2, e as mães dos meninos, 40,3. Em relação à responsividade paterna, para as meninas, encontra-se o escore médio de 24,2, enquanto para os meninos este é de 30,7 (Tabela 2).

Verificou-se significância estatística no escore médio de exigência para pai e mãe, percebido pelas meninas $\left(\mathrm{t}_{(17)}=3.326 ; p=0,004\right)$ e pelos meninos $\left(t_{(30)}=3,701 ; p=0,001\right)$. O mesmo ocorreu para o escore médio de responsividade (pai e mãe) para as meninas $\left(t_{(17)}=3,365 ; p=0,004\right)$ e para os meninos $\left(t_{(30)}=4,552\right.$; $\mathrm{p}=0,000)$.

Observa-se então que as mães têm escores mais altos, tanto de exigência quanto de responsividade, em relação aos filhos. Os dados são congruentes com os estudos de Pacheco, Silveira e Schneider (2008) e com as pesquisas de Teixeira et al. (2004, p.9), que concluíram que:

Os resultados obtidos nas comparações dos níveis de exigência e responsividade atribuídos a pais e mães seguiram um padrão já observado em outros estudos... ou seja, as mães foram percebidas como mais responsivas e exigentes do que os pais, tanto pelas filhas quanto pelos filhos. Tais resultados podem estar confirmando uma maior proximidade da mãe com os filhos, apontada em estudos anteriores, nos quais as mães aparecem como bastante envolvidas na educação e desenvolvimento dos filhos, suplantando em muitos aspectos a participação paterna (grifos nossos).

Embora, culturalmente, o papel de impor regras e limites seja relacionado à figura masculina, na prática, como demonstra o presente estudo, é a mãe quem vem assumindo esse papel. Tais dados são semelhantes com aqueles destacados em outras investigações, como as de Baumrind (1971), Predebon eWagner (2005), Teixeira et al. (2004), Wagner et al. (2002), Wagner, Predebon, Mosmann e Verza (2005) e de Pacheco et al. (2008). Nesse contexto, Wagner et al. (2002) salientaram a importância da comunicação interpessoal na adolescência, tendo observado que as mães, além de estarem ocupando o papel da imposição dos limites para os filhos, também foram consideradas pelos adolescentes da pesquisa como a pessoa com quem eles mais se comunicam e dialogam, na interação familiar.

Contudo, quando os dados são examinados em relação à exigência e responsividade por sexo, encontram-se escores mais altos para os meninos, nas duas dimensões (Tabela 2). As meninas perceberam menores níveis de exigência e responsividade materna e paterna do que os meninos. O escore médio das dimensões exigência e responsividade, combinadas, percebido pelas meninas, foi significativamente mais baixo do que o dos meninos, tanto para exigência $\left(\mathrm{t}_{(47)}=-2.405 ; p=0,020\right)$, quanto para responsividade $\left(t_{(47)}=-2.107 ; p=0,041\right)$. Também se verificou diferença estatisticamente significativa no escore médio de exigência para o pai $\left(\mathrm{t}_{(47)}=-2,206 ; p=0,032\right)$, em relação aos meninos.

Quanto à dimensão responsividade, esta pesquisa encontrou os mesmos resultados obtidos no estudo

Tabela 2. Medidas de centralidade e variabilidade para as Escalas de Exigência e Responsividade (n=62). Assis (SP), 2008.

\begin{tabular}{|c|c|c|c|c|c|c|c|c|c|c|}
\hline \multirow{3}{*}{$\hat{\zeta}$} & \multirow{2}{*}{ Variáveis } & \multicolumn{3}{|c|}{ Meninas } & \multicolumn{3}{|c|}{ Meninos } & \multicolumn{3}{|c|}{ Total } \\
\hline & & $M D$ & M & DP & MD & M & DP & MD & M & DP \\
\hline & Exigência & & & & & & & & & \\
\hline \multirow{5}{*}{ 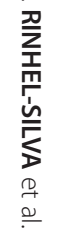 } & Pais ${ }^{(*)}$ & 23,0 & 24,2 & 12,7 & 35,0 & 32,1 & 11,7 & 32,0 & 29,2 & 12,5 \\
\hline & Mães & 37,5 & 36,7 & 7,1 & 40,5 & 39,3 & 6,3 & 39,0 & 38,4 & 6,7 \\
\hline & Combinada & 60,5 & 60,4 & 14,1 & 71,0 & 71,3 & 15,9 & 66,0 & 67,3 & 16,0 \\
\hline & Responsividade & & & & & & & & & \\
\hline & Pais ${ }^{(*)}$ & 28,0 & 24,2 & 14,0 & 32,0 & 30,7 & 12,1 & 31,0 & 28,4 & 13,1 \\
\hline \multirow{2}{*}{ 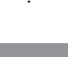 } & Mães & 37,0 & 36,2 & 10,0 & 41,5 & 40,3 & 6,3 & 41,0 & 38,8 & 8,0 \\
\hline & Combinada & 65,5 & 59,8 & 19,1 & 70,0 & 70,6 & 16,1 & 69,0 & 66,6 & 17.9 \\
\hline
\end{tabular}

226

MD: Mediana; M: Média; DP: Desvio-Padrão; ${ }^{(*)}$ Dados perdidos: 4 meninas e 9 meninos não responderam a esta questão. 
de Reichert e Wagner (2007), ou seja, nessa dimensão, os pais apresentaram-se mais responsivos com os filhos do que com as filhas.

Diferentemente, o presente estudo encontrou na dimensão exigência uma divergência da literatura, pois os pais, na percepção dos adolescentes, estão mais exigentes com respeito aos meninos do que quanto às meninas. Pode-se atribuir tal discordância às características específicas dos sujeitos deste estudo, ou seja, os adolescentes participam de programas sociais, residem em territórios críticos de alta vulnerabilidade social, em locais em que se pode encontrar a predominância da drogadição, entre outros fatores geradores de risco. Em decorrência disso, é possível que os pais estejam fazendo maior exigência em relação aos meninos, pois as principais queixas e encaminhamentos aos Programas Sociais advêm do sexo masculino, fato este demonstrado pelo número de meninas e de meninos aqui estudado. Levando em conta a situação de vulnerabilidade, Macedo et al. (2006) encontraram, em seus estudos, que os pais com IPVS alto evidenciam maior rigor na imposição de regras, porque consideram que, quanto maior o risco ao qual os jovens estão expostos, mais explicitada se torna a importância atribuída à obediência, à boa educação e aos limites, pois na visão dos pais, tais qualidades - quando presentes nos jovens - desafiam as crenças que associam a pobreza à delinquência.

Tal divergência dos dados pode ser creditada, igualmente, à maior convivência dos meninos com a figura paterna. Aqui, os meninos apresentaram maior percentual de convivência com a figura paterna, já que, do total de 40, 25 (62,5\%) residiam com pai ou padrasto, enquanto entre as meninas esse percentual é ligeiramente menor (59,1\%, 13 meninas) (Tabela 1). A questão éabordada por Wagner et al. (2002) e Zamberlan e BiasoliAlves (2008), que discutem a importância da figura paterna na relação parental, pois o pai representa para o filho a disciplina, a autoridade e os valores morais.

Para a construção dos estilos parentais, as medidas de centralidade e dispersão foram calculadas conforme os estudos citados por Teixeira et al. (2004, p.7), para pais, mães e ambos, tendo sido realizadas comparações (entre os sexos e entre as respostas dadas quanto a pais e mães): "Devem ser desconsiderados, para análise dos estilos parentais, aqueles casos cujos escores sejam idênticos aos valores das medianas em responsividade materna, paterna e combinada e exigência materna, paterna e combinada". Dessa forma, chega-se aos resultados apresentados na Tabela 3.

Quase a metade das meninas (9 - 42,9\%) considerou as mães como negligentes, enquanto quase metade dos meninos (15 - 41,7\%) atribuiu-lhe a condição de autoritativas. Em relação ao pai, os escores apresentaram-se da mesma maneira, ou seja, a maioria das meninas avaliou-os como negligentes ( 9 - 52,9\%), enquanto a quase maioria dos meninos (13 - 46,4\%) avaliou-os como mais autoritativos.

Os resultados combinados para pai e mãe, de acordo com o sexo, seguiram o mesmo padrão, de modo que, das meninas respondentes, $(n=16), 10(62,5 \%)$ classificaram os pais como negligentes e, entre os meninos respondentes $(n=28), 15(53,6 \%)$ os consideraram

Tabela 3. Estilos parentais para mães, pais e os dois combinados, segundo o sexo do adolescente ( $n=62)$. Assis (SP), 2008.

\begin{tabular}{|c|c|c|c|c|c|c|c|c|}
\hline & \multicolumn{2}{|c|}{ Autoritativo } & \multicolumn{2}{|c|}{ Autoritário } & \multicolumn{2}{|c|}{ Indulgente } & \multicolumn{2}{|c|}{ Negligente } \\
\hline & $n$ & $\%$ & $n$ & $\%$ & $n$ & $\%$ & $n$ & $\%$ \\
\hline \multicolumn{9}{|l|}{ Mãe } \\
\hline Menina & 4 & 19,0 & 4 & 19,0 & 4 & 19,0 & 9 & 42,9 \\
\hline Menino & 15 & 41,7 & 5 & 13,9 & 5 & 13,9 & 11 & 30,6 \\
\hline \multicolumn{9}{|l|}{ Pai } \\
\hline Menina & 4 & 23,5 & 2 & 11,8 & 2 & 11,8 & 9 & 52,9 \\
\hline Menino & 13 & 46,4 & 4 & 14,3 & 4 & 14,3 & 7 & 25,0 \\
\hline \multicolumn{9}{|c|}{ Combinados } \\
\hline Menina & 4 & 25,0 & 1 & 6,3 & 1 & 6,3 & 10 & 62,5 \\
\hline Menino & 15 & 53,6 & 4 & 14,3 & 1 & 3,6 & 8 & 28,6 \\
\hline
\end{tabular}


autoritativos. Para a explicação de tais resultados podem ser levantado como hipóteses o fato de as meninas terem apresentado menor convivência com a figura paterna do que os meninos. Eainda, o fato de os meninos estarem mais expostos a fatores de risco que as meninas, como já discutido anteriormente. Entretanto, a confirmação dessas hipóteses requer a realização de novos estudos.

Não se verificou significância estatística entre os sexos (meninos e meninas) quanto aos quatro estilos parentais ( $\left.\chi^{2}=5,529 ; g l=3 ; p=0,137\right)$. Contudo, fazendo a mesma análise, tendo em vista agora apenas os participantes que classificaram seus pais como autoritativos e negligentes (por serem dois extremos e também por serem os estilos que ocorreram com maior frequência), foi possível notar diferença estatística $p=0,045$ (teste exato de Fisher).

A Figura 1 explicita as porcentagens dos estilos parentais maternos, paternos e combinados, utilizando como ponto de corte a mediana dos dados.

Os valores encontrados revelam que, de $n=44$ jovens, 19 (43,2\%) percebem seus pais como autoritativos, isto é, com altos níveis de exigência e de responsividade, seguidos por $18(40,9 \%)$ que os consideram negligentes, $5(11,4 \%)$ autoritários e $2(4,5 \%)$ indulgentes, na mesma linha de outros estudos (Weber et al., 2003a; Reichert \& Wagner, 2007).

Tais resultados estão compatíveis com outros trabalhos sobre os estilos parentais, os quais apontam que, no estilo autoritativo, os pais estabelecem conduta,

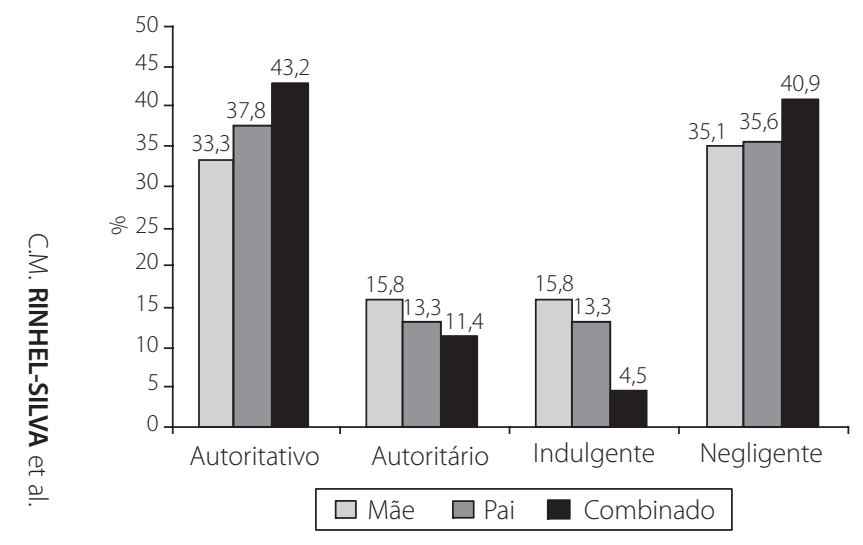

Figura 1. Porcentagem dos estilos parentais para mães, pais e os 228 dois combinados ( $n=62)$. Assis (SP), 2008. valorizam o respeito às regras e reconhecem as qualidades e competências dos filhos, demonstrando interesse por sua vida. Assim, levam os filhos a se relacionar de forma positiva, com competência social, autoestima, autoconfiança, desempenho acadêmico satisfatório, otimismo, menores níveis de ansiedade, depressão e stress, bem como menor propensão a comportamentos antissociais, delinquência e drogas (Baumrind, 1966, 1971; Hutz \& Bardagir, 2006; Steinberg, 2001; Teixeira et al., 2004; Weber, Viezzer \& Brandenburg, 2002; Weber et al., 2003a; Weber et al., 2003b).

No caso específico desta pesquisa, parece que os adolescentes estão avaliando seus pais de maneira mais positiva, em relação à educação, do que eles próprios (pais) acreditam. Entretanto, nota-se diferença mínima entre o estilo autoritativo e o negligente, o que significa que grande número de adolescentes avalia seus pais com baixa exigência e baixa responsividade. E esse dado se torna relevante, na medida em que os filhos criados nesse estilo geralmente apresentam os piores índices de ajustamento entre os quatro outros estilos, com menor índice de competência social e cognitiva, maior nível de ansiedade e depressão, e maior índice de problemas de comportamento (Hutz \& Bardagir, 2006).

Nessa perspectiva, pode-se enfatizar:

Um aspecto de grande importância está no fato de não só saber o que fazer para educar bem, como também saber se o que está sendo feito é interpretado pela criança como se espera. Pode ocorrer no relacionamento pais-filhos uma certa incompatibilidade de percepções e pensamentos, ou seja, a visão que o filho tem sobre os comportamentos dos pais é diferente da visão que os pais têm deles próprios. Pode-se dizer que está havendo uma incompatibilidade de percepções e pensamentos, ou seja, a visão que o filho tem sobre os comportamentos dos pais é diferente da visão que os pais têm deles próprios (Weber, Prado, Viezzer \& Brandenburg, 2004, p.330).

Steinberg (2001) afirma não conhecer nenhum estudo que indique que os adolescentes criados em outros estilos se saiam melhor em suas habilidades do que os filhos de pais com estilo parental autoritativo, independentemente de sua origem racial, social ou mesmo do estado marital de seus pais. Assim, os pais precisam ser firmes em relação a certa autoridade (ou seja, ao nível de exigência) e, ao mesmo tempo, 
responsivos, respeitando e entendendo os direitos dos filhos.

Outro ponto a ser destacado é a importância de os pais constituírem referências positivas para os seus filhos, pois, conforme a pesquisa de Weber et al. (2006), a transmissão intergeracional de estilos parentais aparece com um índice de 91,7\%. Os estudos de La Taille (1996), Postman (2000), Oliveira (2007) e Zamberlan (2008) também enfatizam a responsabilidade dos adultos ou figuras de referência nas relações parentais, nas quais os filhos parecem se espelhar nas atitudes e comportamentos dos pais. Lima (2006) relata, em sua pesquisa, que os adolescentes reproduziram em suas falas o desejo de que sua família futura fosse igual à família de origem, mesmo ressaltando os conflitos vivenciados tanto com os irmãos quanto com os pais. Na mesma perspectiva, Steinberg (2001) salienta que a competência do adolescente é influenciada pelos pais - e não o contrário.

Em resumo, pode-se dizer que os principais resultados deste trabalho indicaram uma divergência em relação aos estilos parentais, quando se considera o sexo dos adolescentes participantes, o que significa que novos estudos devem ser conduzidos, a fim de se verificar tal tendência em populações com essas características específicas.

\section{Considerações Finais}

O estudo realizado permite refletir sobre a importância das relações entre pais e filhos, para o desenvolvimento de programas sociais que envolvam a orientação de pais, no sentido de criar novas práticas que visem a fortalecer os vínculos parentais de famílias sujeitas a vulnerabilidade social.

Os resultados apontam que os pais aparecem como mais exigentes em relação aos meninos e menos exigentes em relação às meninas, dados que diferem daqueles discutidos pela literatura, revelando a necessidade de realizar novos estudos para explorar as dimensões qualitativas dos estilos parentais, a fim de compreender melhor as condutas que permeiam as relações no contexto familiar.

Quando se considera o sexo na avaliação dos estilos parentais, os pais foram percebidos diferentemente pelos adolescentes, ou seja, as meninas caracte- rizaram seus pais como negligentes, e os meninos, como autoritativos.

Diante dos resultados, pode-se questionar se os estilos parentais apresentados seriam específicos da população estudada ou se eles podem ser entendidos como característicos de famílias monoparentais, nas quais a ausência de um dos progenitores poderia estar afetando as relações familiares.

Acredita-se que estudos sobre as relações parentais de indivíduos sujeitos a vulnerabilidade social, como a presente pesquisa, podem representar contribuição significativa à formulação de políticas públicas voltadas à juventude e ao atendimento de suas famílias.

Também é necessária a criação de oportunidades que propiciem diálogo e orientação, não só no sentido de informar os pais sobre o desenvolvimento e as mudanças na fase da adolescência, mas também de salientar a importância do papel parental na educação do filho adolescente. Em acréscimo, é oportuno enfatizar a importância de se criarem espaços e ações que possibilitem uma aproximação entre a percepção e interpretação dos adolescentes quanto aos pais e vice-versa, com a finalidade de fortalecer o papel da autoridade parental para o funcionamento familiar saudável e o bem-estar de seus membros.

\section{Referências}

Baumrind, D. (1966). Efeccts of authoritative control on child behavior. Child Development, 37 (4), 887-907.

Baumrind, D. (1967). Child care practices anteceding three patterns of preschool behavior. Genetic Psychology Monographs, 75 (1), 43-88.

Baumrind, D. (1971). Current patterns of parental authority. Developmental Psychology Monograph, 4 (1), 1-103.

Brasil. Ministério do Desenvolvimento Social. (2006). Plano nacional de promoção, proteção e defesa do direito de crianças e adolescentes à convivência familiare comunitária. Brasília: Autor.

Cecconello, A. M. (2003). Resiliência e vulnerabilidade em famílias em situação de risco. Tese de doutorado não-publicada, Universidade Federal do Rio Grande do Sul, Porto Alegre.

Costa, F. T., Teixeira, M. A. P., \& Gomes, W. B. (2000). Responsividade e exigência: duas escalas para avaliar estilos parentais. Psicologia: Reflexão e Crítica, 13 (3), 465-473.

Darling, N., \& Steinberg, L. (1993). Parenting style as context: an integrative model. Psychological Bulletin, 113 (3), 487-496. 
Goldani, A. M. (1993). As famílias no Brasil contemporâneo e o mito da desestruturação. Cadernos Pagu, 1, 67-110.

Gomide, P. I. C. (2006). Inventário de estilos parentais: modelo teórico, manual de aplicação, apuração e interpretação. Petrópolis: Vozes.

Hutz, C. S., \& Bardagir, M. P. (2006). Indecisão profissional, ansiedade e depressão na adolescência: a influência dos estilos parentais. Psico-USF, 11 (1), 65-73.

La Taille, Y. (1996). A educação moral: Kant e Piaget. In J. Piaget, M. S. S. Menin, Y. La Taille \& L. Macedo (Orgs.), Cinco estudos de educação moral (Coleção Psicologia da Educação). São Paulo: Casa do Psicólogo.

Lima, L. V. B. E. (2006). A família na perspectiva de adolescentes das camadas médias de Belo Horizonte. Monografia não-publicada, Pontifícia Universidade Católica de Minas Gerais, Belo Horizonte.

Maccoby, E. E., \& Martin, J. A. (1983). Socialization in the context of the family: parent- child interaction. New York: Wiley.

Macedo, R. M. S., Kublikowiski, I., \& Berthoud, C. M. E. (2006). Valores positivos e desenvolvimento do adolescente: uma perspectiva dos pais. Revista Brasileira de Crescimento e Desenvolvimento Humano, 16 (2), 38-52.

Oliveira, A. C. F. (2007). A delicada relação entre pais e pais e filhos. Recuperado em novembro 13, 2007, disponível em <www.psicologia.com.pt/artigo $>$.

Pacheco, J. T. B., Silveira, L. M. O. B., \& Schneider, A. M. A. (2008). Estilos e práticas educativas parentais: análise da relação desses construtos sob a perspectiva dos adolescentes. Psico, 39 (1), 66-73.

Pereira, P. A. (1995). Desafios contemporâneos para a sociedade e a família. Revista Serviço Social e Sociedade, 16 (48), 103-114

Postman, N. (2000). O desaparecimento da infância. Rio de Janeiro: Graphia.

Predebon, J. C. F., \& Wagner, A. (2005). Problemas de comportamento na adolescência: configuração familiar e aspectos sociodemográficos. Revista Práxis, 2 (2), 1-11.

Reichert, C. B., \& Wagner, A. (2007). Autonomia na adolescência e sua relação com os estilos parentais. Psico, 38 (3), 292-299

São Paulo (Estado). Fundação Sistema Estadual de Análise de Dados. (2000). Indice paulista de vulnerabilidade social do município de Assis. Recuperado em janeiro 15, 2009, disponível em <http://www.seade.gov.br/produtos/ipvs/ analises/assis.pdf $>$.

Steinberg, L. (2001). We know some things: parent-adolescent relationships in retrospect and prospect. Journal of Research on Adolescence, 11 (1), 1-19.

Teixeira, M. A. P., Bardagi, M. P., \& Gomes, W. B. (2004). Refinamento de um instrumento para avaliar responsividade e exigência parental percebidas na adolescência. Avaliação Psicológica, 3 (1), 1-12.

Wagner, A., Falke, D., Silveira, L. M. B. O., \& Mosmann, C. P. (2002). A comunicação em famílias com filhos adolescentes. Psicologia em Estudo, 7 (1), 75-80.

Wagner, A., Predebon, J. C. F., Mosmann, C. P., \& Verza, F. (2005). Compartilhar tarefas? Papéis e funções de pais e mães na família contemporânea. Psicologia: Teoria e Pesquisa, 21 (2), 181-186.

Weber, L. N. D., Brandenburg, O. J., \& Viezzer, A. P. (2003a). A relação entre o estilo parental e o otimismo da criança. Psico-USF, 8 (1), 71-79.

Weber, L. N. D., Prado, P. M., Viezzer, A. P., \& Brandenburg, O. J. (2004). Identificação de estilos parentais: o ponto de vista dos pais e dos filhos. Psicologia: Reflexão e Crítica, 17 (4). 323-332

Weber, L. N. D., Selig, G. A., Bernardi, M. G., \& Salvador, A. P. (2006). Continuidade dos estilos parentais através das gerações - transmissão intergeracional dos estilos parentais. Paidéia, 16 (35), 407-414

Weber, L. N. D., Stasiack, G. R., \& Brandenburg, O. J. (2003b). Percepção da interação familiar e auto-estima de adolescentes. Alethéia, 17/18, 95-105.

Weber, L. N. D., Viezzer, A. P., \& Brandenburg, O. J. (2002). Relacionamento entre pais e filhos: entre tapas e beijos. Jornal Voz do Paraná, 1760, 6-7.

Zamberlan, M. A. T. (Org.). (2008). Interações familiares-teoria, pesquisa e subsídios à intervençã ( $\left.2^{\mathrm{a}} \mathrm{ed}\right)$. Londrina: EDUEL.

Zamberlan, M. A.T., \& Biasoli-Alves, Z. M. M. (2008). Interações familiares: a perspectiva ecológico-relacional. In M. A. T. Zamberlan (Org.), Interações familiares: teoria, pesquisa e subsídios à intervenção (2a ed.). Londrina: EDUEL. p.1-22.

Recebido em: 21/7/2010

Versão final reapresentada em: 11/10/2011

Aprovado em: 18/10/2011 